\title{
COORDENAÇÃO E GESTÃO PEDAGÓGICA DA ESCOLA
}

\author{
Joaquim Machado*
}

\begin{abstract}
Resumo: A análise da evolução normativa da gestão pedagógica da escola põe em evidência continuidades e ruturas na morfologia organizacional e ajuda a compreender as suas semelhanças jurídicoformais, especialmente se atendermos que, apesar da retórica autonómica, a direção das escolas portuguesas continua centralizada no ministério da educação e nos serviços centrais. Contudo, a análise dos regulamentos internos das escolas mostra que estas não são meras instâncias reprodutoras das leis e, no processo de incorporação das normas centrais, algumas escolas recriam algumas estruturas e assumem caraterísticas organizacionais específicas.

Este artigo faz o mapeamento das diversas estruturas de gestão administrativo-pedagógica de nível intermédio da escola contempladas no plano normativo ao longo dos quarenta anos de democracia e incorporadas nos seus regulamentos internos, assinalando um percurso cheio de continuidades mas com alguma evolução determinada pelas exigências da escola de massas.

Por fim, centra-se no trabalho que os professores desenvolvem no seio das estruturas de gestão intermédia e problematiza a colaboração docente e o papel das lideranças escolares.
\end{abstract}

Palavras-Chave: Estrutura Educativa, Gestão Pedagógica, Liderança na Escola.

\section{Title: COORDINATION AND EDUCATIONAL MANAGEMENT OF SCHOOLS}

\begin{abstract}
The analysis of the regulatory evolution of the pedagogical management of schools puts in evidence continuities and ruptures in organizational morphology and helps to understand their legal and formal similarities, especially if we consider that despite the rhetoric of autonomic Portuguese schools, its direction remains centralized in the ministry education and central services. However, the analysis of the internal regulations shows that schools are not just
\end{abstract}

\footnotetext{
* Faculdade de Educação e Psicologia, Universidade Católica Portuguesa. E-mail: jmaraujo@porto.ucp.pt
} 
reproductive organs of the laws but they recreate some structures and implement specific organization features, in the process of incorporation of the core standards.

This article identifies different intermediate-level structures of administrative and pedagogical management of school contemplated in legislative terms over forty years of democracy and incorporated in its internal regulations, marking a route full of continuities but with some evolution determined by the requirements of school masses. Finally, it focuses on the work that teachers develop within the intermediate-level management structures and discusses the teaching collaboration and the role of school leaders.

Keywords: Educative Structure, Educational Management, School Leadership.

\section{INTRODUÇÃO}

Analisando a situação da administração da educação em Portugal em finais do século XX, João Barroso assinala três facetas da crise que a escola atravessa: 1) a crise de legitimidade do papel centralizador do Estado e a reivindicação de interferência e iniciativa da sociedade local na definição das políticas educativas e na governação das escolas; 2) a crise de governabilidade manifesta no facto de as reformas virem a ser mudadas pelas escolas em vez de as modificarem; 3) a crise do modelo baseado na pedagogia coletiva e no ensino da "mesma coisa, ao mesmo tempo e da mesma maneira, a uma classe de alunos" que se tornou desajustado à maior heterogeneidade da escola para todos, às alterações verificadas na relação pedagógica e à abertura da escola ao meio (1999, pp.130-131). Segundo o autor, a solução para a crise do modelo não está na invenção de um outro modelo alternativo, mas no abandono da própria ideia de "modelo", o que significa admitir "a diversidade de soluções, a pluralidade de iniciativas e a variedade das formas, de acordo com as características específicas de cada situação" (1999, p. 132).

Esta alteração radical comporta o desenvolvimento da autonomia da escola, o que exige, por um lado, o desenvolvimento de formas diversificadas de liderança (individual e coletiva) e, por outro, a transformação da organização e das práticas pedagógicas. De entre as lideranças o autor destaca "as exercidas pelos órgãos de gestão intermédia (direção de grupo e de turma)" afirmando que o seu "mau funcionamento constitui um dos maiores défices das nossas escolas" (1999, p.141). Já relativamente à organização e às práticas, declara que é preciso substituir o princípio da homogeneidade pelo princípio da diversidade, a lógica de uniformização pela lógica de individualização e a rotina da lição pela inquietude do projeto. 
Ao assinalar os órgãos de gestão intermédia, o autor destaca os dois pilares organizativos da escola - a disciplina e a turma - em que se alicerçam as estruturas básicas de coordenação do trabalho docente - o grupo disciplinar e o conselho de turma, no âmbito das quais se desenvolvem lideranças escolares intermédias. Contudo, a escola portuguesa integra hoje diversas outras estruturas de gestão pedagógica intermédia com vista ao desenvolvimento do seu objeto primordial - o desenvolvimento do projeto societário para as jovens gerações assegurado por um grupo profissional com habilitação profissional de nível superior, relativa autonomia de ação e controlo sobre o seu trabalho, o que ajuda a matizar a função de coordenação do trabalho docente.

Este artigo faz o mapeamento das diversas estruturas de gestão administrativo-pedagógica de nível intermédio da escola contempladas no plano normativo ao longo dos quarenta anos de democracia e incorporadas nos seus regulamentos internos, assinalando um percurso cheio de continuidades mas com alguma evolução determinada pelas exigências da escola de massas.

Por fim, centra-se no trabalho dos professores no seio das estruturas de gestão intermédia e problematiza a colaboração docente e o papel das lideranças escolares.

\section{ESTRUTURAS DE GESTÃO PEDAGÓGICA}

A análise da morfologia organizacional da escola no Portugal Democrático mostra que o funcionamento da escola assentou em três órgãos de topo - o conselho diretivo/executivo ou diretor, o conselho pedagógico e o conselho administrativo - centrados fundamentalmente na comunidade escolar: discentes, docentes e não docentes. Na sequência da perspectiva de integração comunitária das escolas e de orientação da sua administração e gestão pelos princípios de democraticidade e de participação de todos os implicados no processo educativo (Lei n. ${ }^{\circ}$ 46/86, de 4 de outubro, art. ${ }^{\circ} 45^{\circ}$ ), sobretudo a partir da última década do século XX emerge um órgão de representação comunitária (a assembleia de escola em 1998, a que sucede o conselho geral em 2008, precedidos, embora em regime de experiência pedagógica, pelo conselho de escola ou de área escolar em 1991).

Os estudos sobre a administração e gestão das escolas ignoram praticamente o conselho administrativo, o órgão institucional que delibera em matéria administrativo-financeira no respeito das regras da contabilidade pública e que manteve sempre na sua composição dois elementos do órgão diretivo e o chefe dos serviços administrativos. Os 
estudos têm incidido sobretudo na repartição de poderes institucionais entre o órgão diretivo, o órgão pedagógico e o órgão de participação comunitária, a respetiva composição e processo de escolha dos seus membros e as perspetivas que inspiram as alterações que têm sido introduzidas.

A análise na legislação sobre o conselho pedagógico das escolas (Portaria n. ${ }^{\circ}$ 679/77, de 8 de novembro, e Decreto-Lei n. ${ }^{\circ}$ 75/2008, de 22 de abril, alterado pelo Decreto-Lei n. ${ }^{\circ} 137 / 2012$, de 2 de julho) permite realçar o sentido da evolução do objeto da ação deste órgão, passando a "orientação pedagógica" a ser atualmente entendida como "coordenação e supervisão pedagógica e orientação educativa, (...) nomeadamente nos domínios pedagógico-didático, da orientação e acompanhamento dos alunos e da formação inicial e contínua do pessoal docente" (Decreto-Lei n. ${ }^{\circ} 137 / 2012$, de 2 de julho, art. ${ }^{\circ} 31 .^{\circ}$ ). A análise mostra também que o âmbito da sua ação pode ultrapassar as fronteiras do estabelecimento e abranger um agrupamento de escolas.

Apesar da continuidade da denominação do órgão pedagógico de topo, a escola tornou-se mais heterogénea na população discente e docente, mais diversificada na função docente e no desenvolvimento do nível de gestão intermédia e, por isso, mais complexa na sua organização (Formosinho, 1992). Tal facto faz com que a Administração educativa reconheça margens de autonomia na ação organizacional, nomeadamente a possibilidade de conceber e desenvolver um projeto educativo próprio e a faculdade de tomar decisões em domínios como a organização pedagógica, a organização curricular, a ação social escolar e a gestão dos recursos humanos, físicos e financeiros (Decreto-Lei n. ${ }^{\circ}$ 115-A/98, de 4 de maio; Decreto-Lei n. ${ }^{\circ}$ 75/2008, de 22 de abril).

Esta evolução reflete-se na composição do conselho pedagógico, nas suas atribuições e competências e nos seus "órgãos de apoio" (Portaria n. 679/77, de 8 de novembro; Portaria n. ${ }^{\circ}$ 970/80, de 12 de novembro), "estruturas de orientação educativa" (Portaria n. ${ }^{\circ}$ 921/92, de 23 de setembro) ou "estruturas que colaboram com o conselho pedagógico e a direção executiva" (Decreto-Lei n. ${ }^{\circ} 115-\mathrm{A} / 98$, de 4 de maio) ou o diretor com vista a "assegurar a coordenação, supervisão e acompanhamento das atividades escolares, promover o trabalho colaborativo e realizar a avaliação de desempenho do pessoal docente" (Decreto-Lei n. ${ }^{\circ} 75 / 2008$, de 22 de abril, art. ${ }^{\circ} 42 .^{\circ}$ ). Assim, se em 1977 o conselho pedagógico era constituído pelos delegados de grupo ou disciplina, representantes dos diretores de turma e representantes dos alunos, atualmente a composição deste órgão é definida no regulamento interno, mas não pode ir para além de dezassete elementos e deve garantir a participação dos coordenadores 
dos departamentos curriculares, bem como "a participação das demais estruturas de coordenação e supervisão pedagógica e de orientação educativa, assegurando uma representação pluridisciplinar e das diferentes ofertas formativas" (Decreto-Lei n. ${ }^{\circ} 137 / 2012$, de 2 de julho, art. $.^{\circ} 32 .^{\circ}$, n..$^{\circ} 1$ ). Compete ainda às escolas definir as formas de participação dos serviços técnico-pedagógicos. Do conselho pedagógico fez sempre parte o dirigente máximo da escola, que lhe preside, sendo exceção em algumas escolas o período de 1998 a 2008, já que o regime de gestão permitia a presidência do órgão por outro professor. Se, em 1977, os membros do conselho pedagógico eram todos eles eleitos pelos pares, atualmente a diversidade de processos de escolha acentua mais a dimensão de designação pelo diretor, órgão de gestão unipessoal e cuja escolha obedece a um processo concursal e escolha pelo conselho geral, a partir de elementos curriculares e do seu projeto de intervenção na escola ou agrupamento.

No entanto, independentemente da diversidade de projetos desenvolvidos e das distintas estruturas pedagógicas, a escola assenta em dois pilares organizativos: a disciplina enquanto unidade do plano de estudos e a turma enquanto célula básica de agrupamento dos alunos (Machado, 2015). São estes dois pilares que determinam a alocação dos professores à escola e que, em 1977, estão na base dos dois principais órgãos de apoio ao conselho pedagógico, o conselho de grupo ou disciplina e o conselho de turma, tendo o primeiro à sua frente um delegado eleito pelos pares e o segundo um diretor designado pelo órgão diretivo.

É certo que, nessa data, previam-se ainda outros órgãos - conselho de ano, conselho de curso e diretor de instalações - mas para todos os efeitos são o conselho de grupo ou disciplina e o conselho de turma aqueles que mais estão ligados com a organização tradicional da escola.

A complexificação do organograma escolar dá-se com a criação dos departamentos curriculares, agrupando professores de várias disciplinas e áreas disciplinares com vista a reforçar a articulação interdisciplinar na aplicação dos planos de estudo e, na sequência das alterações no sistema de avaliação, desenvolver com os diretores de turma e os serviços de psicologia medidas nos domínios da orientação, acompanhamento e avaliação dos alunos e com eles colaborar na elaboração de programas de apoio educativo (Portaria n. $^{\circ}$ 921/92, de 23 de setembro).

Esta nova estrutura é incorporada em 1998 no novo regime de administração e gestão das escolas (Decreto-Lei n. ${ }^{\circ} 115-\mathrm{A} / 98$, de 4 de maio), deixando o legislador de se deter nas atribuições e competências das "estruturas que apoiam o conselho pedagógico" e determinando 
apenas que eles sejam constituídos tendo em vista: a) a articulação curricular na aplicação dos planos de estudo definidos a nível nacional, bem como o desenvolvimento de componentes curriculares por iniciativa da escola ou agrupamento (em 1998, conselho de docentes na educação de infância e no $1^{\circ}$ ciclo do ensino básico e departamentos curriculares nos $2^{\circ}$ e $3^{\circ}$ ciclos e no ensino secundário; em 2008, departamentos curriculares para todos os níveis de educação básica e secundária); b) A organização, o acompanhamento e a avaliação das atividades de turma ou grupo de alunos (educador de infância, professor titular de turma e conselho de turma); e c) a coordenação pedagógica de cada ano, ciclo ou curso (conselho de docentes na educação de infância e no $1^{\circ}$ ciclo; conselho de diretores de turma nos $2^{\circ}$ e $3^{\circ}$ ciclos do ensino básico e no ensino secundário).

Por outro lado, o legislador permite que, no exercício da autonomia pedagógica e curricular, cada escola defina no seu regulamento interno as atribuições e competências das diversas estruturas, mas não deixa de preocupar-se em determinar os requisitos e o processo de escolha do coordenador de departamento: em 1998 requeria-se que fosse profissionalizado, em 2008 que fosse professor titular, em 2012 que seja docente de carreira e, sempre que possível, detentor de formação especializada nas áreas de supervisão pedagógica, avaliação do desempenho docente ou administração educacional; em 1998 seria eleito de entre os docentes que integram o departamento, em 2008 seria designado pelo diretor, em 2012 passa a ser eleito pelo departamento, de uma lista de três docentes propostos pelo diretor.

A sucessão da legislação não significa necessariamente ruturas significativas no plano da ação, mas pode contribuir para compreender o processo de sedimentação das estruturas de organização pedagógica intermédia, a pluralidade de órgãos que o professor integra, a emergência de hierarquias difusas no seio da escola e a concretização de lideranças diversas.

A evolução normativa mostra ainda a emergência e consolidação de outras estruturas entre estes dois pilares organizacionais e o órgão de coordenação pedagógica, nomeadamente o departamento curricular e conselho de diretores de turma, bem como a coordenação de ano, de ciclo ou de curso.

Ao longo dos anos, assumiram sempre maior visibilidade e importância organizacional as estruturas com representantes diretos no conselho pedagógico, mas mantêm-se enraizados na escola os dois pilares organizacionais em que se desenvolve o trabalho docente - o grupo disciplinar, mesmo que remetido para fração do departamento curricular, 
e o conselho de turma. Deles emanam as principais disposições com impacto no desenvolvimento do plano de turma (Decreto-lei n. ${ }^{\circ}$ 115$\mathrm{A} / 98$, de 4 de maio), em torno do qual se realiza a articulação interdisciplinar do plano de estudos, se concretizam estratégias de diferenciação pedagógica e de adequação curricular e se implementam medidas de orientação, acompanhamento e avaliação dos alunos.

\section{A ORGANIZAÇÃO PEDAGÓGICA DAS ESCOLAS}

A análise da evolução normativa da gestão pedagógica da escola contempla um tipo de textos - os normativos legais - que projetam e antecipam, no plano discursivo soluções estruturais e morfológicas de alcance universal, servidas pela força da imposição normativa e hierárquica: "A ação política e administrativa, empreendida através de instâncias legislativas e de órgãos centrais de controlo e de coordenação, é tradicionalmente objeto de fixação textual, apelando a códigos e a regras específicos, a suportes tipificados, a meios de difusão e comunicação bem estabelecidos", como é o Diário da República (Lima, 2011b, p. 166).

$\mathrm{Na}$ verdade, a revisitação dos normativos permite assinalar continuidades e permanências da morfologia escolar no plano legislativo. Mas importa também ver como as escolas interpretam, incorporam e recriam as diferentes alterações legislativas. Por isso, procuramos saber que estruturas de gestão pedagógica as escolas apresentam e procedemos à análise dos regulamentos internos dos doze agrupamentos de escolas de um concelho do norte do país.

Como não poderia deixar de ser, todos os regulamentos contemplam o departamento curricular e o coordenador de departamento, o conselho de turma e o diretor de turma. Referem também o grupo disciplinar, embora com designações diferentes (grupo, subdepartamento, secção) e o conselho e/ou coordenação de diretores de turma. No que respeita à coordenação do trabalho docente na educação de infância e no $1^{\circ}$ ciclo do ensino básico, seis regulamentos referem o conselho de docentes de cada um desses níveis organizativos, mas cuja composição coincide com o departamento curricular, pelo que um regulamento refere expressamente "conselho de docentes para a avaliação".

Constata-se também que os sete agrupamentos que têm cursos de educação qualificante e cursos profissionais dispõem de um conselho de curso, tenha ele esta designação (AECA) ou a de conselho de coordenação (AESM), conselho de diretores dos cursos profissionais (AEAS), conselho de "ofertas educativas" (AEFS) ou de "oferta 
qualificante" (AEDMII), coordenação de "novas oportunidades" (AEM e AER) ou simplesmente de "conselho de diretores de curso" (AEM).

Nove agrupamentos de escolas consideram no seu regulamento interno uma estrutura de coordenação de ano com vista à harmonização das atividades desenvolvidas pelas turmas do mesmo ano de escolaridade, fazendo-a coincidir com 1) o conselho dos diretores de turma de cada ano de escolaridade ou 2) o conselho de docentes do $1^{\circ}$ ciclo do ensino básico de um determinado ano de escolaridade.

Destacamos três agrupamentos (AEMC, AER, AEM) que determinam que, no caso dos $2^{\circ}$ e $3^{\circ}$ ciclos do ensino básico, o conselho de ano é a estrutura pedagógica de coordenação, acompanhamento, orientação e supervisão do trabalho de uma equipa docente que integra todos os professores que lecionam alunos do mesmo ano de escolaridade, incluindo os docentes de apoio educativo e de educação especial que trabalhem com esses alunos.

Num dos agrupamentos, começou-se por experimentar a associação de dois ou mais diretores de turma do mesmo ano de escolaridade com vista à elaboração de um plano comum, experiência essa que depois se alargou a todos os diretores de turma do mesmo ano de escolaridade com planos de turma comuns e, finalmente, evoluiu para a consideração de toda a equipa docente.

Estes agrupamentos inspiram-se no modelo de organização da escola por equipas educativas apresentado em Portugal por Formosinho (1988) e ensaiado em várias escolas que se reclamam da autonomia, da gestão centrada na escola e do empowerment dos professores. Contudo, em bom rigor, as concretizações do modelo nestes agrupamentos mantêm a organização do processo de ensino por turmas independentes, nas quais se baseia a distribuição dos alunos, a distribuição do serviço docente e a organização dos horários docentes, ao mesmo tempo que atribuem a um conjunto de professores um conjunto de turmas contíguas, de modo a fomentar o trabalho colaborativo para potenciar a gestão e o desenvolvimento de atividades de diversificação curricular, bem como potenciam o conselho de ano como centro da coordenação pedagógica e curricular (Formosinho \& Machado, 2014, p. 96).

$\mathrm{Na}$ verdade, o modelo de organização do processo de ensino por equipas educativas consubstancia-se em três dimensões - uma unidade mais ampla que a turma e o agrupamento flexível de alunos, um plano de gestão integrada do currículo e equipas multidisciplinares (Formosinho \& Machado, 2008) - e supõe a cooperação docente na planificação, desenvolvimento e avaliação do processo instrutivo e educativo, bem como a atribuição das tarefas mais apropriadas a cada um, compaginando 
capacidades essenciais à mudança, porquanto os professores são os agentes (e não o objeto) da mudança educativa (Formosinho \& Machado, 2009).

Ao dar primado à dimensão organizativo-institucional da aprendizagem e à criação de condições estruturais que a possibilite, a organização da escola por equipas educativas requer a descentralização da gestão pedagógica e curricular no interior da escola para um nível cuja unidade base não é já a turma, mas um grupo de alunos correspondente a um conjunto de turmas, e exige que se conceba a organização da escola centrada, mais do que na gestão do programa de cada disciplina, no grupo alargado de alunos e na gestão de um projeto curricular integrado e contextualizado. Por isso, não basta o redesenho da gestão pedagógica e curricular, porquanto a reestruturação da escola é o primeiro passo para a mudança da escola, mas mudar as estruturas não é o mesmo que mudar as normas, os hábitos, as habilidades, as crenças e os modos de entender (Fullan, 2002, p. 36).

\section{CULTURAS E PADRÕES DE TRABALHO DOCENTE}

A docência desenvolve-se, atualmente, nas dimensões individual e coletiva e comporta trabalho solitário e trabalho em equipa. A generalização do modo de organização do processo de ensino segundo a tríade turma-professor-sala conduziu à predominância do trabalho solitário em casa e de execução na sala de aula e à consolidação do princípio da privacidade pedagógica como instrumento de compartimentação deliberada do trabalho docente, afastando instâncias de controlo próximo e de apoio sustentado ao trabalho docente. Não estranha, pois, que o diagnóstico de diversas escolas assinalem como aspetos menos conseguidos a pouca consistência do trabalho colaborativo, a incipiente partilha de experiências e de boas práticas pedagógicas e a escassez de espaços e/ou inexistência de tempos comuns aos professores para o trabalho em conjunto e a partilha de experiências. Com efeito, a cultura de ensino individualista, isolada e "privatista" resulta da consolidação sócio-histórica de estratégias e soluções desenvolvidas, sustentadas ou preferidas ao longo do tempo e constitui o enquadramento da aprendizagem da docência, permitindo compreender o que o professor faz e por que o faz (Hargreaves, 1998, p. 186; Formosinho \& Machado, 2009, p. 27).

Por isso, a existência de estruturas de gestão pedagógica e de funções de coordenação justifica-se não apenas pela própria organização do processo de ensino, mas também pela necessidade de introduzir o 
princípio de colaboração como resposta aos problemas imprevisíveis que emergem em contexto escolar e de desenvolver padrões de trabalho conjunto dos docentes num contexto social e educativo em que as soluções são pouco claras e as exigências e expectativas se intensificam (Hargreaves, 1998, p. 277). Trata-se, pois, de um processo que envolve pessoas que trabalham em conjunto com objetivos comuns, assim como valoriza e potencia as experiências e conhecimentos de cada um, ao mesmo tempo que integra tempos e modos de trabalho individual (Roldão, 2007, p. 28).

Nas culturas de colaboração, as relações de trabalho entre os professores tendem a ser espontâneas, voluntárias, orientadas para o desenvolvimento, alargadas no tempo e no espaço e imprevisíveis (Hargreaves, 1998, p. 216-217). Quando a colaboração se torna uma obrigação (direta ou indireta) e se orienta para a execução das determinações que provêm de outros decisores (internos e/ou externos), deparamo-nos com situações de "colegialidade forçada" a realizar em locais e tempos determinados para produzir resultados de grau relativamente elevado de previsibilidade. Como refere Hargreaves, "a colegialidade artificial constitui uma simulação administrativa segura da colaboração" e "substitui as formas espontâneas, imprevisíveis e difíceis de controlar, da colaboração que são, pelo contrário, controladas, contidas e inventadas pelos administradores" (1998, p. 220). São atualmente bastante frequentes os reparos dos professores de sobrecarga de trabalho, rejeitando a "colaboração intensiva" que consome demasiado tempo em prejuízo do trabalho realizado ou a realizar na sala de aula e exige maior flexibilização do tempo de preparação do trabalho com os alunos, quando o que se pretende é que a organização dos horários e a marcação de horas de reunião sejam utilizadas para "libertar os professores em conjunto, ou como estratégia para facilitar a colaboração, a colegialidade, e não para a controlar" (1998, p. 224).

$\mathrm{Na}$ verdade, mesmo nas reuniões de planificação conjunta é possível encontrar exemplos de absorção do tempo pela cultura do individualismo, e não para o desenvolvimento da colaboração e da colegialidade. Assim, os estudos realizados por Lima sobre experiências de colegialidade docente comprovam que as decisões tomadas em grupo pelos professores "chegavam, na maior das hipóteses, a acordos sobre as ênfases (em termos de tempo a dispender com determinadas partes dos conteúdos), o ritmo e a sequenciação dos conteúdos curriculares", mas que "a maioria das suas interações profissionais não se orientava para uma ação coordenada" e que "as poucas interações que tinham essas caraterísticas não se centravam na sala de aula", deixando os professores "de fora da 
sua agenda de contactos os aspetos-chave relativos à observação e à crítica das suas práticas profissionais (2004, p. 67).

Por isso, assume especial relevo o facto de, num dos agrupamentos estudados, se projetar, para o ano letivo de 2015/2016, o desenvolvimento de práticas de observação de aulas por pares quer no âmbito de determinada turma (observação de aulas de professores de disciplinas diferentes com o mesmo conjunto de alunos) quer no âmbito do mesmo ano de escolaridade (professores da mesma disciplina com conjuntos diferentes de alunos). Esta decisão de um conjunto de professores procura romper com a perspetiva de prática isolacionista da sala de aula e alargar a colaboração de forma que ela abarque "o trabalho em conjunto, a observação mútua e a pesquisa reflexiva focalizada, de formas que expandem criticamente a prática, procurando alternativas melhores, na busca contínua do aperfeiçoamento" (Hargreaves, 1998, p. 219).

\section{LIDERANÇA PEDAGÓGICA DISPERSA}

Como se refere acima, a análise da evolução normativa sobre a gestão pedagógica da escola põe em evidência continuidades e ruturas na morfologia organizacional e ajuda a compreender as suas semelhanças jurídico-formais, se atendermos que, apesar da retórica autonómica das escolas portuguesas, a sua direção continua centralizada no ministério da educação e seus serviços centrais. Contudo, a análise dos regulamentos internos das escolas mostra que estas não são meras instâncias reprodutoras das leis e que, no processo de incorporação das normas centrais, algumas recriam estruturas e assumem caraterísticas organizacionais específicas.

O particular relevo que nestas assumem a ação organizacional e os seus atores mostra a insuficiência de uma abordagem de tipo jurídico que deduza exclusivamente da lei as caraterísticas de cada escola concreta e requer estudos que mostrem como "cada escola é e (...) está sendo em cada contexto e a cada momento concreto, habitada por atores sociais e pelas suas respetivas ações" (Lima, 2011b, p. 152).

A proliferação de estruturas de gestão pedagógica intermédia ora propicia a colaboração docente, ora a intensifica e a sua coordenação pode assumir facetas de pendor mais burocrático, mais gerencialista ou mais profissionalmente emancipatório, contribuindo assim para modos distintos de ser e estar sendo escola.

$\mathrm{Na}$ verdade, não bastam a criação de órgãos e estruturas de coordenação do trabalho docente e a sua inscrição no organograma da escola para que surjam equipas docentes eficazes, sendo certo que os 
órgãos e estruturas são determinantes na estruturação do trabalho docente. Não bastam as capacidades de cada membro da equipa; é preciso que sejam apoiados processos e comportamentos orientados para o trabalho em equipa de modo a favorecer a complementaridade das capacidades individuais. Não basta enunciar o objetivo que rege a criação da equipa docente; é preciso o compromisso partilhado face a um objetivo comum. Não basta o estabelecimento de objetivos de desempenho; importa que eles sejam partilhados e haja a consciência de que não podem ser atingidos senão em equipa. Não basta o rigor técnico da abordagem estabelecida para o trabalho em equipa; é preciso que os membros da equipa se sintam mutuamente responsáveis por ela.

Por outras palavras, a consideração do trabalho dos professores no âmbito das diversas estruturas que integram exige que se considere a liderança como função inerente à equipa e não apenas como característica individual do coordenador formal (Lorenzo Delgado, 2005, pp. 370-371), supondo o seu exercício o domínio de processos técnicos de gestão (saber como se dirige a equipa docente, conhecer e reunir a documentação necessária, condução de reuniões, etc.), bem como capacidade para encontrar significados para o que ocorre na escola e na equipa (crenças e incertezas dos professores, problemas disciplinares, conflitos, etc.) e para encontrar saídas e transformar situações menos positivas em ocasiões de crescimento conjunto e aprofundamento do trabalho em equipa. De igual modo, exige que se considere a liderança como uma função partilhada, exercida de modo colegial pelos participantes no desenvolvimento curricular e pedagógico do ano de escolaridade. Tal não obsta, no entanto, que, à semelhança da administração e gestão geral da escola, a coordenação das distintas estruturas de gestão pedagógica seja encarada ora numa perspetiva de abordagem burocrática, ora numa perspetiva de abordagem gerencialista, que enforma e conforma os professores de forma compósita.

Por isso, importa também deslindar que lideranças são ativadas e que aprendizagens fazem os professores enquanto coletivo que desenvolve a sua ação numa organização onde convivem a uniformidade e a diversidade, a prescrição e o incentivo à inscrição, a submissão e a autonomia profissional, a burocracia e a adhocracia, a retórica da colegialidade e a socialização num padrão de trabalho fragmentado, a tradição e a inovação na prática pedagógica (Formosinho, Machado \& Mesquita, 2015; Lima, 2011a). 


\section{CONCLUSÃO}

A disciplina enquanto unidade do plano de estudos e a turma enquanto célula básica de agrupamento dos alunos constituem os dois pilares organizativos da escola pós-primária, nos quais se alicerçam as estruturas básicas de coordenação do trabalho docente, o grupo disciplinar e o conselho de turma. Entretanto, outras estruturas de nível intermédio foram emergindo nas escolas como resposta organizacional à complexidade crescente, embora sem romper com aqueles pilares estruturantes da organização do processo de ensino.

Algumas escolas ensaiam estruturas alternativas inspiradas no modelo de equipas educativas, aprofundando modos de conjugar o trabalho individual e o trabalho em conjunto, rompendo com a perspetiva isolacionista da sala de aula e buscando o aperfeiçoamento profissional e o desenvolvimento organizacional.

O estudo destas iniciativas das escolas mostra que o seu êxito depende da descentralização interna da gestão pedagógica e curricular, da organização do processo de ensino focado na gestão de um projeto curricular integrado e contextualizado e da consideração da liderança como função inerente à equipa e não apenas como característica individual do coordenador formal.

\section{FONTES E BIBLIOGRAFIA}

Barroso, J. (1999). A escola entre o local e o global: perspectivas entre o local e o global. Lisboa: Educa.

Formosinho, J. (1988). Proposta de organização do $2^{o}$ ciclo do ensino básico em agrupamentos educativos. Trabalho elaborado para a Comissão de Reforma do sistema educativo. Braga: Universidade do Minho (policopiado).

Formosinho, J. (1992). O dilema organizacional da escola de massas, Revista Portuguesa de Educação, 5 (3), 23-48, Universidade do Minho - Braga.

Formosinho, J. \& Machado, J. (2008). Currículo, pedagogia e organização. As Equipas Educativas como modelo alternativo, Currículo sem Fronteiras, 8 (1), 5-16, jan/jun.

Formosinho, J. \& Machado, J. (2009). Equipas Educativas: para uma nova organização da escola. Porto: Porto Editora.

Formosinho, J. \& Machado, J. (2014). As equipas educativas e o desenvolvimento das escolas e dos professores. In J. Machado \& J. M. Alves (orgs.), Melhorar a Escola: Sucesso escolar, disciplina, 
motivação, direção de escolas e políticas educativas (pp. 91-195). Porto: Universidade Católica Editora

Formosinho, J., Machado, J. \& Mesquita, E. (2015). Formação, Trabalho e Aprendizagem: Tradição e inovação nas práticas docentes. Lisboa: Edições Sílabo.

Fullan, M. (2002). Las Fuerzas del Cambio: Explorando las profundidades de la reforma educativa. Madrid: Ediciones Akal.

Hargreaves, A. (1998). Os Professores em Tempo de Mudança: O trabalho e a cultura dos professores na idade pós-mopderna. Lisboa: Mc Graw-Hill.

Lima, J. A. (2004). O currículo construído: Da autonomia da escola à colaboração profissional entre os docentes, Revista de Estudos Curriculares, 2 (1), 57-84. APEC - Braga.

Lima, L. C. (2011a). A escola como organização educativa: Uma abordagem sociológica. São Paulo: Cortez Editora.

Lima, L. C. (2011b). Administração Escolar: Estudos. Porto: Porto Editora

Lorenzo Delgado, M. (2005). El liderazgo en las organizaciones educativas. Revisión y perspectivas atuales, Revista Española de Pedagogía, 232, setiembre/diciembre, 367-388.

Machado, J. (2015). Organização e coordenação do trabalho docente: O conselho de ano como estrutura de gestão pedagógica intermédia. Comunicação no Seminário Trabalho Docente e Liderança Escolar, Faculdade de Educação e Psicologia da Universidade Católica Portuguesa, Porto, 25 de fevereiro de 2015.

Roldão, M. C. (2007). Colaborar é preciso: Questões de qualidade e eficácia no trabalho dos professores, Noesis, 70, julho/setembro, 2429. DGIDC/ME - Lisboa. 